\title{
Вертебральные болевые синдромы у подростков: дискуссионные вопросы
}

\author{
Р. А. Банникова, О. А. Андруская, А. А. Погребняк
}

Национальный университет физического воспитания и спорта Украины, Киев, Украина

\begin{abstract}
Резюме. В огляді відображено дані про поширення, механізми виникнення, діагностику та реабілітацію больового синдрому в спині у дітей та підлітків. Визначено фактори ризику виникнення вертебральних больових синдромів. Підкреслено, що вони значно погіршують якість життя та негативно позначаються на фізичному та психічному стані дитини. Висвітлено сучасні тенденції та деякі невирішені проблеми діагностики, профілактики та реабілітації вертеброгенної патології у підлітків.
\end{abstract}

Ключові слова: вертебральний больовий синдром, профілактика, фізична реабілітація.

Summary. The review recorded data on the prevalence and mechanisms of occurrence, diagnosis and rehabilitation of pain in the back in children and adolescents. Factors of risk of vertebral pain syndromes. Emphasized that they significantly impair quality of life and adversely affect the physical and mental state of the child. The modern trends and some unsolved problems of diagnosis, prevention and rehabilitation of vertebral pathology in adolescents.

Key words: vertebral pain back, prophylaxis, physical rehabilitation.

Постановка проблемы. Боль в спине - дорсалгию - называют пандемией современного общества, и результаты эпидемиологических исследований подтверждают эту точку зрения. Так, по данным экспертов ВОЗ, периодически повторяющимися болями в спине страдает до $60 \%$ населения развитых стран [33]. Этиологическими факторами данной патологии в 80 \% случаев являются дегенеративные изменения в позвоночнике и остеохондроз, спондилез, спондилолистез, спондилоартроз, сколиоз, деформации тел позвонков [1, 23].

Согласно сорормировавшимся на сегодняшний день представлениям о сути болевого синдрома, боль - это феномен, в генезе которого переплетаются анатомический, фризиологический, психологический и социальный компоненты [19]. Независимо от причины и локализации возникновения, боль существенно изменяет качество жизни пациентов, уровень их физической и жизненной активности. Эти компоненты болевых ощущений в спине составляют симптомокомплекс, известный, как «вертебральный болевой синдром». Боль в спине чаще всего развивается в возрасте от 20 до 50 лет и наиболее выраженно она ощущается в 50-64. Пик болевых ощущений приходится на 35-45 лет $[7,20]$. Особую обеспокоенность вызывает тот фракт, что 10-44 \% детей и подростков также жалуются на боль в спине $[31,35]$. Такие жалобы у школьников 11-14 лет выявлены [34] у $24 \%$ детей в Англии, у $20 \%$ - в Швейцарии и у
17,6-18 \% - в Финляндии. В США ежегодно регистрируется 5000 случаев заболеваний позвоночника у детей [33, 34]. Статистических данных о распространенности дорсалгий среди детского и подросткового населения Украины нет, как нет и четких стандартизированных критериев диагностики, комплексных методов восстановительного лечения и профилактики, что обосновывает более углубленное изучение данной проблемы.

Исследование проведено в соответствии со Сводным планом НИР в сфере физической культуры и спорта на 2011-2015 гг. по теме 4.4. «Усовершенствование организационных и методических основ программирования процесса фризической реабилитации при дисфрункциональных нарушениях в различных системах организма человека».

Цель исследования: обобщение современных научно-методических знаний о вертебральном болевом синдроме у подростков и принципах фризической реабилитации.

Методы исследования: анализ, обобщение и систематизация данных научно-методической литературы.

Результаты исследования и их обсуждение. По современным представлениям, к основным показателям цивилизованности страны относятся уровень здоровья и продолжительность жизни ее населения.

Негативные тенденции в состоянии здоровья детей и подростков в Украине за последнее десятилетие приобрели устойчивый характер и 
стали еще более очевидными, поскольку не преодолен демографический кризис, и доля детского населения в возрасте до 16 лет меньше доли взрослого населения старше 60 лет [2, 16].

Риск возникновения разных заболеваний у детей школьного возраста увеличивается в связи с ухудшающейся экологической обстановкой, малоподвижным образом жизни, неблагоприятной наследственностью и другими проблемами XXI века. Вместе с тем в период обучения в школе происходит интенсивное развитие организма ребенка, который чутко реагирует на ухудшающие здоровье фракторы [18, 23].

Наиболее характерными отклонениями в состоянии здоровья учащихся являются: патология органов зрения, заболевания опорно-двигательного аппарата, сердечно-сосудистой системы, органов дыхания, пищеварения, нарушения обмена веществ [13].

Среди заболеваний, существенно влияющих на состояние здоровья и особенно небезопасных своими последствиями, выделяется патология костно-суставного аппарата и соединительной ткани. Значительная часть из них - неправильная осанка, пороки развития позвоночника, дегенеративно-дистрофические изменения позвоночника (остеохондроз, спондилоартроз и т.д.) и остеопения /остеопороз - сопровождается болевым синдромом, нарушениями фрункциональной активности, ограничением свободы перемещения, отягощая тем самым не только жизнь самого больного и его семьи, но и общества в целом $[4,7,8]$. В связи с этим еще в начале XXI века созрела идея организации Международной декады костей и суставов (The Bone and Joint Decade 2000-2010), направленной на изменение сложившейся ситуации с целью привлечения внимания широкой общественности во всех странах мира к данной проблеме [4].

В рамках Декады приоритетными были определены исследования и разработки в области следующих пяти направлений: болезни суставов (остеоартроз, ревматоидный артрит и др.); остеопороз; боли в спине; тяжелые травмы конечностей; детские мышечно-скелетные нарушения.

Боли в области спины (дорсалгии) занимают второе место по частоте обращений к врачам (после острых респираторных заболеваний) и третье - по частоте случаев госпитализации [10].

Увеличение частоты регистрации боли в спине среди детского населения (причем чаще среди девочек, чем мальчиков) свидетельствует о стойкой тенденции этой патологии к омоложению. Существуют данные, что истоки дорсалгий у взрослых лежат в детстве [22, 27, 32]. Диапазон частоты встречаемости болевого синдрома в спине среди детей и подростков, по данным зарубежных эпидемиологических исследований, колеблется от 10 до $44 \%$ [31, 35], хотя совсем еще недавно этот диапазон составлял 12-26\% [6].

По биологическому происхождению боль можно расценивать в качестве «парламентера болезни», выдвигающего ультиматум об опасности и неблагополучии в организме, направленный на мобилизацию защитных процессов, восстановление повреждений ткани и нормальной жизнедеятельности [1]. В основе болевого синдрома могут лежать самые разнообразные причины, которые принято разделять на две основные группы: вертеброгенные (спондилогенные), связанные с патологией позвоночника, и невертеброгенные, которые вызваны растяжением связок и мышц (миофасциальные), соматическими заболеваниями, психогенными факторами и др. [10, 25].

Вертеброгенная (спондилогенная) дорсалгия в 60-90 \% случаев обусловлена дегенеративно-дистрофрическими процесами в позвоночнике [10]. Вместе с тем существуют и другие спондилогенные причины дорсалгий, среди которых - метаболические состояния, приводящие к остеопении/остеопорозу, аномалии развития и дисплазии позвоночника. Дисплазия соединительной ткани (ДСТ) - аномалия тканевой структуры, проявляющаяся в снижении содержания отдельных видов коллагена или в нарушении их соотношения, что приводит к ослаблению прочности соединительной ткани многих органов и систем и, как следствие, - к нарушению их фрункции [11]. Клинические проявления ДСТ чрезвычайно вариабельны. Проявлениями дисплазии соединительной ткани опорно-двигательного аппарата являются астеническое телосложение, гипермобильность суставов, плоскостопие, нарушение осанки (сколиоз и синдром «прямой спины»), дископатия (грыжи), деформации грудной клетки, аномалии зубного ряда, повышенная растяжимость кожи. Клиническое течение ДСТ определяется как проградиентное - в возрасте 12-16 лет отмечается максимальная клиническая манифестация френотипических и клинических признаков [5, 21]. Восстановительное лечение при ДСТ, по мнению многих исследователей, наиболее целесообразно проводить именно в подростковом возрасте [5, 11].

Практикующие врачи боль в спине обычно связывают с дегенеративно-дистрофическими изменениями позвоночника. Однако, на сегодняшний день, единой теории развития остеохондроза позвоночника у детей и подростков 
не существует, и вообще выдвинутые концепции немногочисленны. По всей вероятности, затруднения в научном обосновании возникновения и развития остеохондроза у детей связаны с анатомо-функциональными особенностями их костно-суставной системы. В отличие от взрослых, у которых питание межпозвонковых дисков осуществляется исключительно путем дифффузии, так как сосуды в этой зоне облитерированы, у детей до 7-12 лет кровоснабжение дисков сохранено, что требует иного подхода к концепции развития раннего юношеского остеохондроза.

Одними из главных факторов, предрасполагающих к раннему развитию остеохондроза, считаются, тем не менее, гиподинамия и длительные статические перегрузки позвоночника.

Так, выдвинутая С. А. Егоровой концепция развития остеохондроза позвоночника у детей базируется на фракторах «пускового механизма» (наследственной предрасположенности, особенностях конституции, аномалии позвонков и др.; длительных неадекватных статических нагрузках; травмах опорно-двигательного аппарата) и реализующих фракторах (нарушении и асимметрии мышечного тонуса, изменении сроков и этапов моторного развития ребенка в результате формирующегося неадекватного двигательного стереотипа) [9].

В то же время накопленный практический опыт свидетельствует, что у большей части детей с дорсалгиями не всегда удается выявить конкретные болезни и анатомические изменения со стороны различных структур позвоночника, включенных в подкласс МКБ-10 «Дорсопатии»:

- дорсопатии, вызванные деоормацией позвоночника, дегенерациями межпозвонковых дисков без их протрузии, спондилолистезами;

- спондилопатии;

- дорсалгии.

Даже у взрослых целый ряд хронических болевых синдромов либо не имеют точно изученной причины, либо связаны с несколькими патогенетическими фракторами. Что же касается боли в спине у детей и подростков, то этот вопрос вообще пока остается открытым.

В общей сложности фракторы риска возникновения боли в спине делятся на предрасполагающие и провоцирующие [22].

Предрасполагающие факторы, в свою очередь, делятся на некорригируемые и корригируемые. К некорригируемым относятся такие:

- неблагоприятная наследственность - может реализоваться в особенностях соматогенной, психогенной, гормональной, иммунологической, биохимической конституции, особое место занимают врожденные нарушения синтеза соединительной ткани (такие, как дифференцированные синдромы соединительнотканной неполноценности - синдромы Морфана, Эларса и синдром недифроеренцированной дисплазии соединительной ткани; MASS-френотип, синдром гипермобильности суставов);

- пол (преимущественно женский) и гормональный статус;

- возраст (средний и пожилой, у детей - пубертатный чаще, чем младший);

- семейная предрасположенность.

К корригируемым фракторам принадлежат следующие:

- статико-динамические перегрузки;

- отсутствие регулярной фризической активности (занятий фризкультурой);

- малоподвижный образ жизни;

- эпизодические большие фризические нагрузки, наличие резких перепадов в фризических нагрузках;

- нарушения осанки (сколиоз, кифоосколиоз, сутулость);

- частые простудные заболевания;

- ожирение;

- заболевания пищеварительного тракта и печени;

- психосоматические фракторы, эмоциональные поведенческие проблемы;

- злоупотребление алкоголем, курение;

- пристрастие к жареному, копченому, солениям и к продуктам, содержащим большое количество пуриновых оснований;

- нерациональное питание (недостаток кальция, излишек или недостаток магния, избыток фоссрора и марганца, недостаток йода, баланс фртора, цинка, меди, стронция, алюминия и других элементов).

На фоне предрасполагающих фракторов достаточно одного провоцирующего, чтобы возникла боль в спине. К таким факторам относятся:

- резкое локальное или общее переохлаждение;

- неадекватное фризическое движение или натяжение мышцы у лиц со слабо развитым мышечным корсетом;

- длительность и поза пребывания за компьютером и перед телевизором;

- острый эмоциональный стресс.

Что касается вопроса о возможных причинах развития вертебральных болевых синдромов у детей, то пока он является дискутабельным, и высказываемые разными авторами предположения по этому поводу довольно противоречивы. В целом же большинство авторов [28, 30, 34] 
выделяют четыре основные группы фракторов риска развития болевых синдромов в спине у детей:

- антропометрические особенности;

- фракторы образа жизни;

- механический груз (главным образом вес школьной сумки);

- психологические, социальные и поведенческие фракторы.

Боль в спине - не моноэтиологическое состояние и клинические ее проявления могут иметь весьма разнообразный характер [7]. Следует отметить отсутствие строгого параллелизма между наличием боли в спине у детей и подростков и результатами параклинического исследования позвоночника. Поэтому для постановки правильного диагноза и выбора тактики восстановительных мероприятий ведущее значение имеет тщательная клиническая оценка статуса больного ребенка, в том числе состояния костно-мышечной системы.

Современные подходы к ведению пациентов с дорсалгией базируются на купировании болей, предупреждении хронизации болевого синдрома, обеспечении условий для проведения полноценного курса реабилитационных мероприятий, профрилактике рецидива [26]. Поскольку для болей в спине прямая зависимость между анатомическими изменениями и клинической ситуацией нехарактерна, проблема точной диагностики, определения степени тяжести и, соответственно, практической помощи, своевременной профилактики, восстановительного лечения и реабилитации детей с болевым синдромом остается недостаточно изученной [22]. Традиционные методы и средства фризической реабилитации, применяемые в восстановительном лечении взрослых больных с патологией позвоночного столба, не дают стойкого терапевтического эффекта у подростков, что побуждает к поиску и разработке новых современных реабилитационных технологий, так как существующие программы не отличаются большим здоровьефрормирующим потенциалом. Основой для разработки приоритетных направлений профилактики и реабилитации должны стать выявленные диагностические критерии, фракторы риска и закономерности фрормирования патологии позвоночника. Одним из методов профилактики возникновения у детей и подростков болей в спине является использование эргономических принципов (удобная мебель, жесткая постель, правильная поза при сидении, вес школьной сумки-рюкзака в пределах $10 \%$ массы тела ребенка, ношение рюкзаков на обоих плечах и т.д.).
Алгоритм реабилитационных мероприятий при дорсалгиях должен включать следующие позиции:

- устранение болевых ощущений;

- уменьшение мышечного спазма;

- укрепление мышечно-связочного корсета позвоночника;

- восстановление нормальной амплитуды движений.

Современная классическая система реабилитационных мероприятий при болях в спине основана на выделении трех этапов [1].

- Начальный (или период стабилизации). Задачи в острой фразе: снять боль, расслабить и растянуть тоническую мускулатуру и механически разгрузить позвоночный столб.

- Развивающий (или период мобилизации). Задачи в подострой фразе: увеличение объема движений и расширение двигательной активности.

- Тренирующий (период реактивации). Задачи: укрепление мышечного корсета и устранение мышечного дисбаланса.

Создание оптимальных условий для развития и формирования костно-суставного аппарата у подростков является главной задачей системы реабилитационных мероприятий. Кинезитерапия, проводимая по методу доктора Бубновского С. М. с использованием суставной гимнастики и элементов стретчинга, - путь модернизации программы фризической реабилитации подростков с болью в спине. Реабилитация должна начинаться в максимально ранние сроки с целью предупреждения хронизации болевого процесса. В дальнейшем усилия должны быть направлены на профиллактику рецидивов.

Наилучшие способы профилактики боли в спине у подростков - активный образ жизни и хорошая фризическая форма, поддержание которой требует определенных уточнений и соблюдения рационального двигательного режима, включающего освоение правильного выполнения двигательных навыков повседневной жизни, занятия адекватными видами фризкультуры и спорта [14].

Боль в спине любой интенсивности всегда влияет на качество жизни и жизненную активность подростка, нарушая их в большей или меньшей степени. Результаты изучения качества жизни позволяют сравнить результаты разных реабилитационных программ и методов лечения, а также определить индивидуальную реакцию пациента на болезнь. Наиболее простыми тестами для оценки качества жизни являются опросники Роланда-Морриса, Medical Outcomes Study Short 
Form (SF-36) и ECOS-16 (преимущественно для пациентов с нарушениями структурно-функционального состояния костной ткани) [5, 21-23].

\section{Выводы.}

В последнее десятилетие в структуре заболеваний костно-суставной системы, имеющих большое медико-социальное значение, у лиц молодого возраста существенно возросла вертеброгенная патология, основными клиническими проявлениями которой являются боль в спине, ограничение движений и снижение качества жизни.

Традиционные средства фризической реабилитации, применяемые в восстановительном

\section{Литература}

1. Баринов А. Н. Современные методы лечения боли в спине / А. Н. Баринов // Медицина неотложных состояний. - 2012. - № 2(41). - С.60-66.

2. БогатирьоВа Р. В. Генетико-демографічні процеси серед населення України / Р. В. Богатирьова, О.В.Линчак, О. І. Тимченко // Журн. НАМН України. - 2012. № 1(18). - C.81-91.

3. Воловар О. С. Фенотипові ознаки дисплазії сполучної тканини у пацієнтів із захворюваннями скронево-нижньощелепного суглоба / О. С. Воловар // Укр. мед. часопис. -2013 . - № 2(94). - С.188-192.

4. Вялков А. И. Основные задачи Международной Декады (The Bone and Joint Decade 2000-2010) в совершенствовании борьбы с наиболее распространенными заболеваниями опорно-двигательного аппарата в России / А. И. Вялков, Е. И. Гусев, А. Б. Зборовский, В. А. Насонова // Науч.-практ. ревматология. - 2001. - № 2. - С.4-15.

5. ГлотоВ А. В. Влияние восстановительного лечения в условиях санатория на показатели качества жизни у подростков с дисплазией соединительной ткани /А. В. Глотов, С. В. Добрых, Е. А. Белоус, О. В. Плотникова // Вопр. курортологии, ффизиотерапии и лечеб. фриз. культуры. 2008. - № 3. - С. 38-40.

6. Горленко О. М. Метаболічно-дегенеративні захворювання хребта в дітей. Провідні фрактори ризику, порушення ланок гомеостазу / О. М. Горленко, М. Л. Щербак, Н. А. Кушнир // Пробл. остеології. - 2006. - Т. 9, № 2-3. - С.16-19.

7. Дамулин И. В. Боли в спине: клинические и лечебные аспекты / И. В. Дамулин, П. А. Семенов // Терапевт. арх. - 2009. - № 6. - С.78-82.

8. ЕгороВа И. А. Показатель качества жизни как критерий эффективности восстановительного лечения больных с заболеваниями позвоночника / И. А. Егорова, А. Д. Бучнов, В. В. Матвиенко // Вестн. восстановит. медицины. 2007. - № 3. - C. 42-46.

9. Егорова C. A. Концепция развития остеохондроза позвоночника у детей и задачи оздоровительной физической культуры / С. А. Егорова // Междунар. науч.-практ. коно. «Научное обоснование фризического воспитания, спортивной тренировки и подготовки кадров по фризической культуре и спорту»: материалы конф. - Минск: БГУФК, 2009. - С. 86.

10. ИВаноВа М. Ф. Дорсалгия, обусловленная дегенеративно-дистрофической патологией позвоночника / лечении взрослых с болью в спине, не оказывают стойкого терапевтического эфрфекта у подростков, что побуждает к поиску, научному обоснованию и разработке новых реабилитационных технологий.

Перспективы дальнейших исследований будут направлены на создание эфрфективных реабилитационных программ с использованием суставной гимнастики и элементов стретчинга, способствующих повышению функциональных возможностей, уменьшению степени выраженности болевых синдромов, профилактике рецидивов и улучшению качества жизни подростков с вертеброгенной патологией.

\section{Referense}

1. Barinov A. N. Modern methods of treatment of back pain / A. N. Barinov / / Medical emergency conditions. 2012. - N 2 ( 41). - P. 60-66.

2. Bogatirova R.V. Genetic and demografichni process sered population of Ukraine ( R.V. Bogatirova, O.V. Linchak, O. I.Timchenko / / J. of NAMS of Ukraine. - 2012. N 1 (18). - P. 81-91.

3. Volovar O. S. Fenotipovi sights displaziï spoluchnoï tkanini have patsientiv iz zahvoryuvannyami skronevo - nizhnoschelepnogo Suglob / O. S. Volovar / / Ukrainsky medichny chasopis. - 2013. - N 2 (94). - P.188-192.

4. Vyalkov $A$. I. The main objectives of the International Decade (The Boneand Joint Decade 2000-2010) to improve the fight against the most common diseases of the musculoskeletal system in Russia / A. I. Vyalkov, E. I. Gusev, A. B. Zborovsky, V. A. Nasonova / / Scientific-practical rheumatology. - 2001. - N 2. - P. 4-15.

5. Glotov A. V. Effect of restorative treatment in a sanatorium on the quality of life in adolescents with connective tissue dysplasia / A. V. Glotov, S.V. Dobryh, E. A. Belous, O. V. Plotnikova // Questions of the resorts, physiotherapy and therapeutic physical culture. - 2008. - N 3. - P. 3840.

6. Horlenko O. M. Metabolichno-degenerativni zahvoryuvannya ridge ditey. Providni factorization riziku, torn down lanok homeostasis /O. M. Gorlenko, M. L. Scherbak, N. A. Kushnir / /Problems osteologii. - 2006. - Vol. 9, N 2-3. - P. 16-19.

7. Damulin I. V. Back pain : clinical and therapeutic aspects / I. V. Damulin, H. M. Semenov / /Therapeutic Archives. - 2009. - N 6. - P.78 - 82.

8. Egorova I. A. With zabolevaniyami pozvonochnika / I. A. Egorova, A. D. Buchnov, V. V. Matvienko / / Herald of regenerative medicine. -2007 . $-\mathrm{N}$ 3. - P. 42-46.

9. Egorov S. A. The concept of development of osteochondrosis children and tasks of improving physical training / S. A. Egorova / / Intern. Sci. and practical. Conference «Scientific substantiation of physical education, sportivnoytrenirovki and pidgotovki fizicheskoykulture and training in sport»: materialykonf. - Minsk: BGUFK, 2009. P. 86.

10. Ivanova M. F. Dorsalgia caused by degenerative-dystrophic spinal pathology /M. F. Ivanova, S. K. Yevtushenko / / Novostimeditsiny and Pharmacy in the world. - 2006 . N 17 ( 199). - P. 9-13. 
М. Ф. Иванова, С. К. Евтушенко //Новости медицины и фрармации в мире. - 2006. - № 17(199). - С. 9-13.

11. Кадурина Т. И. Дисплазия соединительной ткани. Руководство для врачей / Т. И. Кадурина, В.Н.Горбунова. - СПб., 2009. - 714 с.

12. КолесникоВа И. А. Особенности фрормирования здоровья и физическая подготовленность детей и подростков в период школьного обучения: автореф. дис. на соискание учен. степени канд. мед. наук / И. А. Колесникова. Архангельск, 2008. - 26 с.

13. Медведовська Н. В. Сучасний стан здоров'я підлітків України / Н. В. Медведовська // Современ. педиатрия. - 2010. - № 6 (34). - С. 14-16.

14. Медицинская реабилитация: рук. для врачей / [под ред. В. А. Епифанова]. - М.: МЕДпресс-информ, 2005. -328 с.

15. Милюкова И. В. Лечебная гимнастика при нарушениях осанки у детей / И. В. Милюкова, Т. А. Евдокимова. М.: Эксмо, 2004. -128 с.

16. Мойсеєнко P. О. Аналіз та тенденції захворюваності дитячого населення України / Р. О. Мойсеєнко, Я. І. Соколовська, Т. К. Кульчицька // Современ. педиатрия. - 2010. - № 3(31). - С.13-17.

17. Мукина Е. Ю. Анализ состояния детской заболеваемости в России в свете снижения общей культуры здоровья населения / Е. Ю.Мукина, Ю. Ю. Мелихов / К Культура фриз. и здоровье. - 2011. - № 6(36). - С. 54-56.

18. Неділько В. П. Стан фрізичного здоров'я дітей шкільного віку та шляхи його підвищення / В. П. Неділько, Т. М. Камінська, С. А. Руденко // Перинатология и педиатрия. - 2009. - № 2 (38). - С. 72-74.

19. Поворознюк В. В. Боль в нижней части спины / В. В. Поворознюк, О. В. Литвин, Т. В. Орлик // Доктор. 2003. - № 1. - С. 31-37.

20. Поворознюк В. В. Боль в нижней части спины / В. В. Поворознюк // Лікування та діагностика. - 2004. № 3. - С. 31-36.

21. Поворознюк В. В. Синдром гіпермобільності суглобів у дітей та підлітків / В. В.Поворознюк, О.І.Подліанова // Пробл. остеології. - 2009. - Т.10, № 4. - С. 49-59.

22. Поворознюк B. В. Боль в нижней части спины у детей. Распространенность. Причины. Механизмы развития. Особенности диагностики у детей / В. В. Поворознюк, М. И. Иващенко // Новости медицины и фрармации в мире. - 2010. - № 6 (312). - С. 9-13.

23. Поворознюк В. В. Вікові та статеві особливості вертебрального больового синдрому / В. В. Поворознюк, Т. В. Орлик, Н. В. Григор'єва // Пробл. остеології. 2011. - Т.14, № 2. -С. 20-25.

24. Самосюк І. З. Больові синдроми / І. З. Самосюк, Н. І. Самосюк, М. В. Чухраев, О. М. Чухраева. - К., 2007. $216 \mathrm{c}$.

25. Статинова E. A. Вертебральные болевые синдромы / Е. А. Статинова, С. В. Селезнева // Новости медицины и фрармации в мире. - 2006. - № 17(199). С. 9-13.

26. Товажнянская Е. Л. Современные подходы к комплексной терапии болевых синдромов в области спины / Е. Л. Товажнянская // Междунар. неврол. журн. - 2012. № 2 (48). - C.14-19.

27. De Bie. Back pain in adolescent / Bie De, B.Staal / Annual. Europ. Congress of Rhuematology. - 2003. Abs.SPOO97. - P. 31.

28. El-Metwally $A$. Risk factors for development of nonspecific musculoskeletal pain in preteens and early adolescents: a prospective 1-year follow-up study / A. El-Metwally,
11. Kadurin T. I. Connective tissue dysplasia. Guide for Physicians / T. I. Kadurina, V. N. Gorbunova // St. Petersburg, 2009 . $-714 \mathrm{~s}$.

12. Kolesnikova I. A. Osobennostiformirovaniya Zdorov'ya and physical fitness of children and podrotkov in periodshkolnogoobucheniya : dissertation on soiskanieuchenoystepeni candidate of medical sciences / I. A. Kolesnikova. - Arkhangelsk,2008. - 26 p.

13. Medvedovska N. V. Suchasni mill Zdorovya pidlitkiv Ukrainy / N. V. Medvedovska / / Contemporary Pediatrics. - 2010. - N 6 (34). - P. 14 - 16.

14. Medical Rehabilitation : A Guide for Physicians / Ed. V. A. Epifanova. - Moscow: MEDpress-Inform, 2005. $328 \mathrm{~s}$.

15. Milyukova I. V. Therapeutic gimnastika in posture disorders in children / I. V. Milyukova, T. A. Evdokimova. Moscow: Eksmo, 2004. - $128 \mathrm{p}$.

16. Moyseenko R. O. Analiz that tendentsiï zahvoryuvanosti Dityache population of Ukraine / R. O. Moyse€nko, Ya. I. Sokolovska, T. K. Kulchitska // Sovremennaya pediatriya. 2010. - N 3 (31). - P.13-17.

17. Mukina E. J. Analysis of the state of child morbidity in Russia to reduce the overall light culture zdorovya population / E.Yu. Mukina, Yu.Yu.Melihov / / Culture and physical health. - 2011. - N 6 (36 ). - P. 54-56.

18. Nedilko V. P. Stan fizichnogo Zdorov'ya ditey shkilnogo viku that Roads Ahead Yogo pidvischennya / V. P. Nedilko, T. M. Kaminska, S. A. Rudenko // Perinatology and pediatrics. - 2009. - N 2 (38). - S.72-74.

19. Povoroznyuk V. V. Pain in the lower back / V. V. Povoroznyuk, O. V. Litvin, T.V.Orlik // Dr. - 2003. - N 1. P. 31-37.

20. Povoroznyuk V. V. Pain in the lower back / V. V. Povoroznyuk / / Likuvannya that diagnostika. - 2004. - N 3. P. 31-36.

21. Povoroznyuk V. V. Syndrome gipermobilnosti suglobiv have ditey that pidlitkiv /V. V. Povoroznyuk, O. I. Podlianova // Problems osteologii. - 2009. - Vol. 10, N 4. - P. 4959.

22. Povoroznyuk V. V. Pain in the lower back in children. Prevalence. Causes. Pathogenesis. Diagnostics in children / V. V. Povoroznyuk, M. I. Ivashenko // Novosti mediciny I pharmatsii v mire. - 2010. - N 6 (312). - C. 913.

23. Povoroznyuk V. V. Vikovi that statevi osoblivosti bolovogo vertebral syndrome / V. V. Povoroznyuk, T. V. Orlik, N. V. Grigor'eva // Problems osteologii. - 2011. - Vol. 14, N 2. - P. 20-25.

24. Samosyuk I. Z. Bolovi syndrome / I. Z.Samosyuk, N. I. Samosyuk, M. V. Chuhraev, O. M. Chuhraeva. - Kiev, 2007. - $216 \mathrm{p}$.

25. Statin E. A. Vertebral pain syndromes / E. A. Statinova, S. V. Selezneva // News of medicine and pharmacy in the world. - 2006. - № 17 (199). - P. 9-13.

26. Tovazhnyanskyy E. L. Sovremennye podhody to complex syndromes terapiibolevyh oblastispiny / E. L. Tovazhnyanskaya / / International Journal of neurological. - 2012. N 2 (48). - P. 14-19.

27. De Bie. Back pain in adolescent / Bie De, B. Staal / / Annual. Europ. Congress of Rhuematology. - 2003. - Abs. SPOO97. - P. 31.

28. El-Metwally $A$. Risk factors for development of nonspecific musculoskeletal pain in preteens and early adolescents: a prospective 1-year follow-up study /A. El-Metwally, J. J. Salminen, A. Anvinen // BMC Musculoskeletal Disorders. - 2007. - N8. - P. 46. 
J. J. Salminen, A. Anvinen // BMC Musculoskeletal Disorders. - 2007. - N 8. - P. 46.

29. Turner P. Y. Back pain in childhool / P. Y. Turner, J. H. Green, C. S., Galasco //Spain. - 2004. - N 14. P. 812-814.

30. Feldman D. E. Risk factors for the development of low back pain in adolescence / D. E. Feldman, I. Shrier, M. Rosignd // Am. J. Epidemid. - 2001. - N 154. - P. 30-36.

31. Pellis F. Prevalence of Low Back Pain and Its Effect on Health-Related Quality of Life in Adolescents / F. Pellis, F. Balagu, L. Rajmil // Arch. Pediatr. Adolesc. Med. 2009. - N 163(1). - P.65-71.

32. Power $C$. Predictors of low back pain onset in a prospective British study / C.Power, J.Frank, C.Hertzman // Am. J. Public. Health. - 2001. - N 91. - P.1671-1678.

33. Hayashi Y. Bone diseases with Pain. Osteoporosis / Y. Hayashi // Clin. Calcium. - 2007. - Apr.17(4). - P. 606612.

34. Watson K. D. Low back pain in school child-ren: occurrence and characteristics / K. D.Watson, A. C. Papageorgion, Y. T. Jones / / Pain. - 2002. - N 97. - P.87-92.

35. Watson K. D. Low back pain in schoolchildren: the role of mechanical and psychosocial factors / K. D. Watson, A. C. Papageorgion, Y. T. Jones // Arch.Dis. Child. - 2003.N 88. - P.12-17
29. Turner P. Y. Back pain in childhool / P. Y. Turner, J. H. Green, C. S. Galasco // Spain. - 2004. - N 14. P. 812-814.

30. Feldman D. E. Risk factors for the development of low back pain in adolescence / D. E. Feldman, I. Shrier, M. Rosignd // Am. J. Epidemid. - 2001. - N 154. P. 30-36.

31. Pellis F. Prevalence of Low Back Pain and Its Effect on Health-Related Quality of Life in Adolescents / F. Pellis, F. Balagu, L. Rajmil // Arch. Pediatr. Adolesc. Med. 2009. - 163(1). - P. 65-71.

32. Power $C$. Predictors of low back pain onset in a prospective British study / C. Power, J. Frank, C. Hertzman // Am. J. Public. Health. - 2001. - N 91. - P. 16711678.

33. Hayashi Y. Bone diseases with Pain. Osteoporosis / Y. Hayashi / / Clin. Calcium. - 2007. - Apr.17(4). - P. 606612.

34. Watson K. D. Low back pain in school children: occurrence and characteristics / K. D.Watson, A. C. Papageorgion, Y. T. Jones / / Pain. - 2002. - 97. - P. 87-92.

35. Watson K. D. Low back pain in schoolchildren: the role of mechanical and psychosocial factors /K. D. Watson, A. C. Papageorgion, Y. T. Jones // Arch.Dis. Child. 2003. - N 88. - P. 12-17. 